\title{
Supply Chain Systems Architecture and Engineering Design: Green-field Supply Chain Integration
}

\author{
Petar Radanliev \\ University of Oxford, Engineering Sciences Department, OeRC, 7 Keble Road, Oxford, England, UK, OX1 \\ 3QG, Email: petar.radanliev@,oerc.ox.ac.uk
}

\begin{abstract}
This paper developed a new theory for supply chain architecture, and engineering design that enables integration of the business and supply chain strategies. The architecture starts with individual supply chain participants and derives insights into the complex and abstract concept of green-field integration design. The paper presented a conceptual system for depicting the interactions between business and supply chain strategy engineering. The system examines the decisions made when engineering the business strategy, with regards to the supply chain design. The system derived with a new understanding of how strategies are integrated, and what are the implications for engineering successful strategies. The study revealed that supply chain design is not considered in great detail before architecting the business strategies. Thus, companies consequentially experience supply chain problems that are likely to be detrimental to the growth potentials. The paper also derived with the findings that proactive and pre-emptive involvement of supply chain participants in the strategy engineering process, would lead to a more robust strategic design.
\end{abstract}

Keywords: supply chain architecture; green-field strategic engineering

\section{INTRODUCTION}

Strategic engineering requires accepting the world and acting upon that world, followed by configuring architectures from evaluating the outcomes of success or failure (Pettigrew 1977, Melnyk et al., 2013). Strategic engineering also requires a consensus on objectives (Qu et al. 2010, Sakka et al., 2011, Leng and Chen, 2012), and in relation to organisational performance, it must be focused on addressing the operational aspect of strategy design (Perez-Franco et al., 2010, Córdova et al., 2012). These complexities and uncertainties create the demand for further investigation of the relationship between business and supply chain strategy architecture.

This study examines what decisions are made for accepting the realities in a given business environment when architecting the business strategy, with regards to the supply chain design. The research aim, is to develop new theory for architecting the individual company's business strategy in a manner that can be integrated in in a green-field supply chain design. The objective is to derive with a new understanding of how the strategies are integrated and implemented, and what are the implications for designing successful green-field strategies. The research differentiates from literature on redesigning existing strategies and is focused on designing new, green-field (non-existent until formulated) strategies.

Consequently, the research is focused on conceptual architectures for formulating a system for relating individual strategic engineering to integrated strategic design. The conceptual design applies business architectures to integrate individual, into collaborative business engineering. The aim of this paper is to systematically analyse strategy abstention and absence of operational capabilities, to determine the right level of integration. The integration design required a synchronised investigation and analysis of how several operational strategies can be performed simultaneously.

The alternative is to relate individual functional strategies without extracting specific designs related to the supply chain collaborated performance. This would hardly lead to improved performance, because even within one company, there are a number of operational designs, requiring different operational strategies, which are not isolated entities (Kaplan and Norton 1996, Frohlich and Westbrook 2001, Jayaram and Tan 2010, Bryceson and Slaughter 2010, Prajogo and Olhager 2012, Sukati et al. 2012). 


\section{LITERATURE REVIEW}

Existing literature on supply chain strategy architecture leads towards: (1) demand for a product and product life cycle (Fisher, 1997); (2) internal and external factors (Narasimhan et al., 2008); (3) level of integration (Frohlich and Westbrook, 2001); and (4) interdependence and organisational compatibility (Mentzer et al., 2001). This literature outlines the supply chain engineering criteria that has not been combined and applied to build an architecture for supply chain design.

Furthermore, supply chain design represents a section of the hierarchical chain of corporate, business and functional level strategies (Narasimhan et al., 2008). The supply chain design is a dynamic concept (Melnyk et al., 2013), and should be analysed in an individual context (Dubois et al., 2004) with a hierarchical method for network design (Dotoli et al., 2005) and Analytical Target Cascading for deconstructing a supply chain into a hierarchical tree (Qu et al., 2010). Similarly to the supply chain design decomposition method (Schnetzler et al., 2007).

This approach can be combined with case study for verifying and testing the results (Dotoli et al., 2005, Qu et al., 2010). Activities can be investigated to determine the actual instead of the intended outcomes (Cigolini et al., 2004) and the structural elements should be based on the business models (MartínezOlvera and Shunk, 2006), while the architecture should be grounded on present strategies (PerezFranco et al., 2010). This creates a gap in literature that has not been addressed until present.

Some studies attempts to address this gap and supply chain strategy, design, tactic and operations have been placed in a conceptual system supported by a mathematical model (Ivanov, 2009). Systems engineering simulations have also been applied to gain the optimum values and corresponding parameters of a conceptual supply chain system (Hafeez et al., 1996). However, these methods lack the necessary details regarding how the method can be applied in additional real world scenarios.

The literature reviewed reveals the existing tools and mechanism which can enable the process of architecting the design for a new conceptual framework for engineering the green-field supply chain integration. From those tools, the hierarchical method for network design was identified as most suitable for integration design, and the case study approach for verifying the result. This approach can be strengthened by building upon the principles from the 'Supply Chain Design Decomposition' (Schnetzler et al. 2007) for hierar- chical decomposing of a complete supply chain, combined with the techniques from customer-productprocess-resource (CPPR) (Martínez-Olvera and Shunk, 2006) and Analytical Target Cascading (ATC).

The proposed formulation method would enable (1) anticipating the supply chain elements that arise from multiple supply chain participants; (2) include the participants' main aims and objectives, and (3) demystify the process of getting from the present to the required stage. Such supply chain engineering method would enable anticipating operational capabilities through internal competencies and by considering inter-organisational integration in combination with internal operations reformulation.

\section{RESEARCH METHODOLOGY}

The research methods applied in the study include case study, action research and field-tests. This study was performed on the mining industry in North Wales and the participants were selected through convenience sampling. To formulate a green-field supply chain, the mining industry (coded as $\mathrm{C}_{1}$ ) was required to integrate with companies from four related industries. The mining industry needed a retailer for virtual quarries (coded as $\mathrm{C}_{2}$ ), civil engineering company (coded as $\mathrm{C}_{3}$ ), logistic company (coded as $\mathrm{C}_{4}$ ), and a distribution centre (coded as $\mathrm{C}_{5}$ ).

The diversity of the population, represented in the supply chain participants, is analysed with reference to the 'Industry Classification Benchmark' to determine the industry representativeness. If the diversity displayed in the sample data findings was established as segmented into company or industry boundaries, the sample data could have been considered as being heavily influenced. In that case, further sampling could have been required to further develop the strategy formulation method. However, the industry diversity displayed in the 'Industry Classification Benchmark' confirmed that the aggregated sample data does not belong to a company or industry. This eliminated the industry dominating factor of company biasing from the formulation methods.

The pool of people interviewed were proportionally representative of the directorial level, managing level, and the operational level supervisors of the supply chain consortium. Only part of the interviews were predetermined in the initial selection and the rest were chosen based on the development of the case study research, this process corresponds with existing literature (Patton, 2002). 
The method selection are aimed at eliminating the obstacles in extracting tacit strategic interests and are focused at enabling the process of critical analysis. The critical analysis is based on evidence extracted through verbalism, or reworded and distilled through content and discourse analysis. The emerging design was presented in a concept summary map, outlined in an explicit form and evaluated with the study participants to obtain respondents validations.

The critical analysis engages a range of sources to validate the theory and starts with defining the strategy architectures of individual supply chain participants from implicit into an explicit form. The second step develops the idea, to derive insights into the complex and abstract concept of business and supply chain integration. The case study approach serves as tools for extracting and relating individual strategic architectures to integrated strategic design. The process results with a conceptual system, validated through action research and field-tested to eliminate obstacles presented in extracting tacit strategic interests.

The process of ensuring validity of the conceptual system applied qualitative research techniques as recommended in existing literature (Easterby-Smith et al., 2002, Gummesson, 2000, Eriksson et al, 2008, Perez-Franco et al., 2010). Conceptual validity is further confirmed through open and categorical coding to analyse the qualitative data. This represents a timetested complimenting method for grounded theory (Charmaz, 2006). Open coding provides a reliable representation of the data collected, while categorical coding subsequently recognises the profounder concepts in the data (Goulding, 2002). In this process, discourse analysis is applied to evaluate and interpret the connotation behind the explicitly stated strategy (Eriksson et al 2008), along with tables of evidence (Eisenhardt, 1989) and conceptual maps (Miles and Huberman, 1984) to present graphical analysis. The research study involved secondary data review and series of 20 qualitative interviews, followed by 2 group discussions, one with experts external to the supply chain and one group discussion with supply chain internal experts.

\section{BUSINESS AND SUPPLY CHAIN STRATEGY INTEGRATION}

\subsection{Formulate the individual strategic architectures in an explicit form}

The emerging conceptual design initiates by identifying individual supply chain participants' principles in the form of sentences that represent the interest of all the participants in the formulation. These statements were used to extract the principles and a new strategic architecture representative of all the companies (coded as $\mathrm{C}_{\mathrm{N}}$ ).

This enables investigating the interests of individual participants, to aggregate a set of principles (coded as $\mathrm{P}_{\mathrm{N}}$ ) from the sum of companies $\left(\mathrm{C}_{\mathrm{N}}\right)$, enabling individual areas of integration to be identified. This presents the first tenet: in integrated green-field design, the architecture must represent the integrated principles of the supply chain group (coded as IPN) instead of being representative of the individual interest of the lead company (coded as $\mathrm{C}_{1}$ ). The emerging design process advocates that the principles are representative of the sum of companies $\left(\mathrm{C}_{\mathrm{N}}\right)$. To achieve this, firstly the sum of strategic principles $\left(\mathrm{PN}_{\mathrm{N}}\right)$ of each individual company must be identified (C) and grouped together (coded into $\mathrm{C}_{\mathrm{N}} \cdot \mathrm{P}_{\mathrm{N}}$ ) to ensure coverage of strategic principles (Figure 1).

Figure 1: Formulation method for integrating individual principles into green-field business strategy

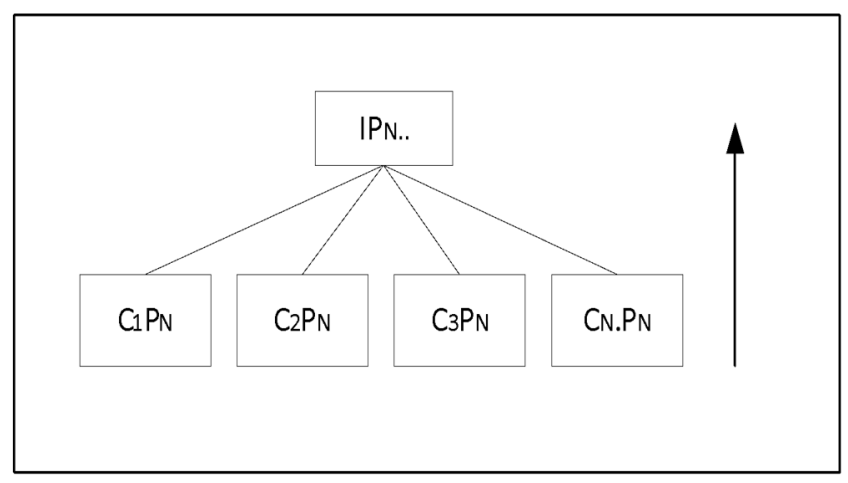

Source: Prepared by the author

To identify individual strategic principles a number of data collection methods have been applied. The first source for collecting data related to individual strategies and strategic principles was internal and external documents. 


\subsection{System evaluation through case study with the sec- ond supply chain participant}

The recommended process involves critically analysing the strategies of individual companies and progressively identifying and building their strategic principles. The process continued with the second company (coded as $\mathrm{C}_{2}$ ) analysed and their business strategy (coded as S). The analysis of the second company strategy (coded as $\mathrm{C}_{2} \mathrm{~S}$ ) presented a very straight forward statement, which presents the temptation to disregard the potential in terms of sufficiency for formulating strategy. It must be emphasised that it is not the words that are being analysed but the idea behind the quoted statement. The fact that the statement was quoted in the direct format, as derived during the data collection, eliminates the perception that the statement represents oversimplification of their business strategy. The idea behind the simple statement in fact represents multiple ideas. The analysis of secondary data from internal documents continued until the principles related to the green-field architecture were identified. The extracted sentences are narrowed to the required context.

The process applied open and categorical coding, to internal documents to investigate the relationship between the individual strategic principles and the integrated business strategy. The objective of the exercise was to narrow the idea behind the sentences to relate to integration. The case study resulted with a set of statements that represented the individual strategic principles of the integrated business strategy, as outlined below.

- $\left(\mathrm{C}_{2} \mathrm{P}_{1}\right)$ Secure position in the key markets.

- $\left(\mathrm{C}_{2} \mathrm{P}_{2}\right)$ Keep a close relationship.

- $\left(\mathrm{C}_{2} \mathrm{P}_{3}\right)$ Invest in engineering technology.

- $\left(\mathrm{C}_{2} \mathrm{P}_{4}\right)$ Provide civil engineering expertise.

- $\left(\mathrm{C}_{2} \mathrm{P}_{5}\right)$ Provide waste management expertise.

- $\left(\mathrm{C}_{2} \mathrm{P}_{6}\right)$ Develop models for land remediation.

- $\left(\mathrm{C}_{2} \mathrm{P}_{7}\right)$ Capture substantial aftermarket service.

The set of principles identified are first validated during the interviews with $\left(\mathrm{C}_{2}\right)$. Secondly the relevance of the identified pillars to the green-field formulation was validated through group discussion with executive level participants (group A) from the supply chain consortium $\left(\mathrm{CN}_{\mathrm{N}}\right)$. The new process is designed specifically in the context of this study for extraction, analysis, coding and categorising the process.

\subsection{System evaluation through case study with the third supply chain participant}

The analysis of the terminal and logistics providing company $\left(\mathrm{C}_{3}\right)$ presented a different example. It must be recognised that not all companies have defined their business strategies in equally straight forward identifiable statements. To generalise and further confirm the validity of the data collection a different approach was applied. The business strategy is recorded as initial introductory statement, followed by description of multiple strategies. The description presented multiple strategic ideas that are quoted in direct format.

Having identified the $\left(\mathrm{C}_{3} \mathrm{~S}\right)$, content and discourse analysis was also applied to the passages, combined with open and categorical coding. The set of pillars were validated; firstly through group discussion with $\left(\mathrm{C}_{3}\right)$; secondly, through group discussions with $\left(\mathrm{C}_{\mathrm{N}}\right)$. The process is outlined in Figure 2. Resulting with specific principles related to the green-field formulation.

- $\left(\mathrm{C}_{3} \mathrm{P}_{1}\right)$ Provide network of terminals.

- $\left(\mathrm{C}_{3} \mathrm{P}_{2}\right)$ Invest in rail terminal technology.

- $\left(\mathrm{C}_{3} \mathrm{P}_{3}\right)$ Increase freight flow.

- $\left(\mathrm{C}_{3} \mathrm{P}_{4}\right)$ Open virtual quarries.

- $\left(\mathrm{C}_{3} \mathrm{P}_{5}\right)$ Provide fully integrated service.

Figure 2: Extracting and relating individual principles to integrated business principles

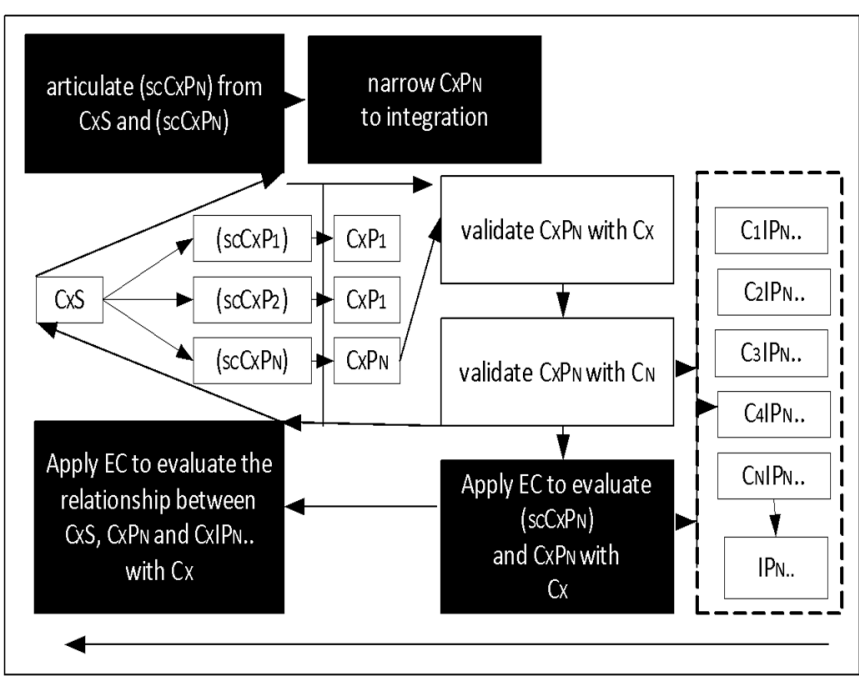

Source: Prepared by the author

\subsection{System evaluation through case study with the fourth supply chain participant}

The method for extracting the strategic pillars from the fourth company (coded as $\mathrm{C}_{4}$ ) was completely different from the previous methods. The method applied involved extracting reference principles from external documents and validating the principles with the management team of $\left(\mathrm{C}_{4}\right)$. Further validation of the passages was performed with interviewing all operational level managers, to confirm that $\left(\mathrm{C}_{4}\right)$ operations are compatible with the identified principles. 
The passages that described the strategy were collected through external sources and analysed in exact wording. The passages were presented to the operational managers to identify the strategic principles relevant to $(\mathrm{C} 4)$. The discussions resulted with a set number of principles. Before taking the extracted principles as actual representation of the $\left(\mathrm{C}_{4}\right)$ strategy, the principles were presented and validated with the management team. The extraction is representative of the earlier process outlined in Figure 2 and strengthens the validity of the emerging method. The process resulted with 7 principles related to supply chain integration.

- $\left(\mathrm{C}_{4} \mathrm{P}_{1}\right)$ Invest in rail technology.

- $\left(\mathrm{C}_{4} \mathrm{P}_{2}\right)$ Provide rail freight logistics.

- $\left(\mathrm{C}_{4} \mathrm{P}_{3}\right)$ Carry a wide variety of slate by-product.

- $\left(\mathrm{C}_{4} \mathrm{P}_{4}\right)$ Offer high value rail transport.

- $\left(\mathrm{C}_{4} \mathrm{P}_{5}\right)$ Develop responsive and effective transport.

- $\left(\mathrm{C}_{4} \mathrm{P}_{6}\right)$ Provide track maintenance.

- $\left(\mathrm{C}_{4} \mathrm{P}_{7}\right)$ Provide effective rail transloading.

\subsection{System evaluation through case study with the fifth supply chain participant}

The method for identifying and extracting the strategic principles from the fifth company involved a series of interviews and group discussions. The managers of $\left(\mathrm{C}_{5}\right)$ preferred to keep their strategy implicit and preferred not revealed it because it could leave them open to competitors. The example from $\left(\mathrm{C}_{5}\right)$ represents the most straight forward process for extracting the strategic principles, because the principles are given. The process is outlined in Figure 3. Their strategic principles were generalised by the executive director and given as:

$\left(\mathrm{C}_{5} \mathrm{P}_{1}\right)$ Increase productivity and profits.

$\left(\mathrm{C}_{5} \mathrm{P}_{2}\right)$ Maximise the value of by-product sales.

$\left(\mathrm{C}_{5} \mathrm{P}_{3}\right)$ Provide site for building infrastructure.

$\left(\mathrm{C}_{5} \mathrm{P}_{4}\right)$ Develop a distinct brand identity.

$\left(\mathrm{C}_{5} \mathrm{P}_{5}\right)$ Optimise the supply chain distribution.
Figure 3: Extracting and relating individual principles to integrated business principles - applied to (C5)

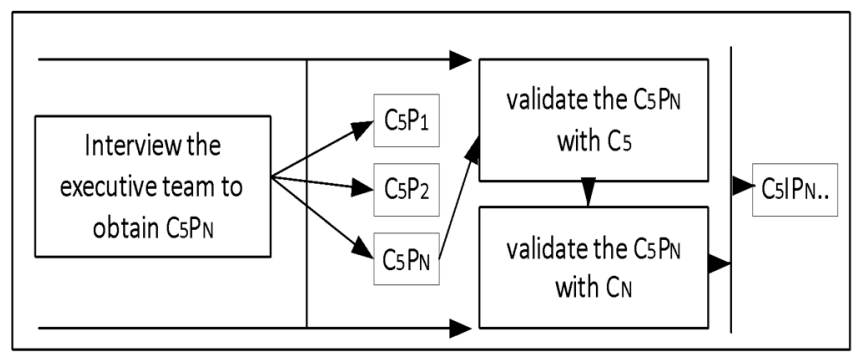

Source: Prepared by the author

\subsection{Analysis and evaluation of the system}

The system for extracting strategic principles specific to the supply chain strategy outlined 5 different methods for identifying and extracting tacit strategic principles from individual companies that need to be integrated into a formulation. This study does not claim that the system is all inclusive, and the requirement to apply different approaches to different case studies confirms that all inclusive systems are not likely to produce the desired results. The resulting conclusion from applying the extraction process to five case studies is that the principles from $(\mathrm{CNS})$ can be extracted with multiple methods. The focus should be placed on determining and validating the $\left(\mathrm{C}_{\mathrm{N}} \mathrm{PN}\right)$ and narrow the principles to integration by validating the principles individually before validating the principles with the group of $\left(\mathrm{C}_{\mathrm{N}}\right)$ to determine the integrated $\left(\mathrm{C}_{\mathrm{N}} \mathrm{PP}_{\mathrm{N}}\right)$.

\subsection{Conversion from tacit to explicit strategy}

The process of converting tacit into an explicit strategy presents a dilemma. The dilemma emerges because without visualising the explicit and implicit aspects of individual strategies, it is impossible to extract the required strategic elements and concepts. On the other hand, the process of making strategy explicit leaves the strategy open for criticisms and attack from competitors (Quinn, 1977) and promotes 'rigidity and inertia' (Mintzberg, 1990). This mind-set was identified in $\left(\mathrm{C}_{5}\right)$. However, other literature supports the process of making strategy explicit stating that articulating strategy is essential to simplify and integrate the strategy (Love et al., 2002). This approach was accepted by $\left(\mathrm{C}_{1,2,3,4)}\right)$. 
Therefore, explicit strategy approach was accepted, because tacit strategic interests are required in an explicit form for the supply chain integration. This enabled the conceptual design to leap from the visible into the invisible aspects of the integration and formulation question. This process starts from evaluating single quotes and leads to the essential elaboration of the phenomenon investigated, resulting with a conceptual system (Figure 4) for integrating individual principles into integrated architecture.

Figure 4: Conceptual system for supply chain strategy engineering of individual principles into a green-field business architecture and integration design

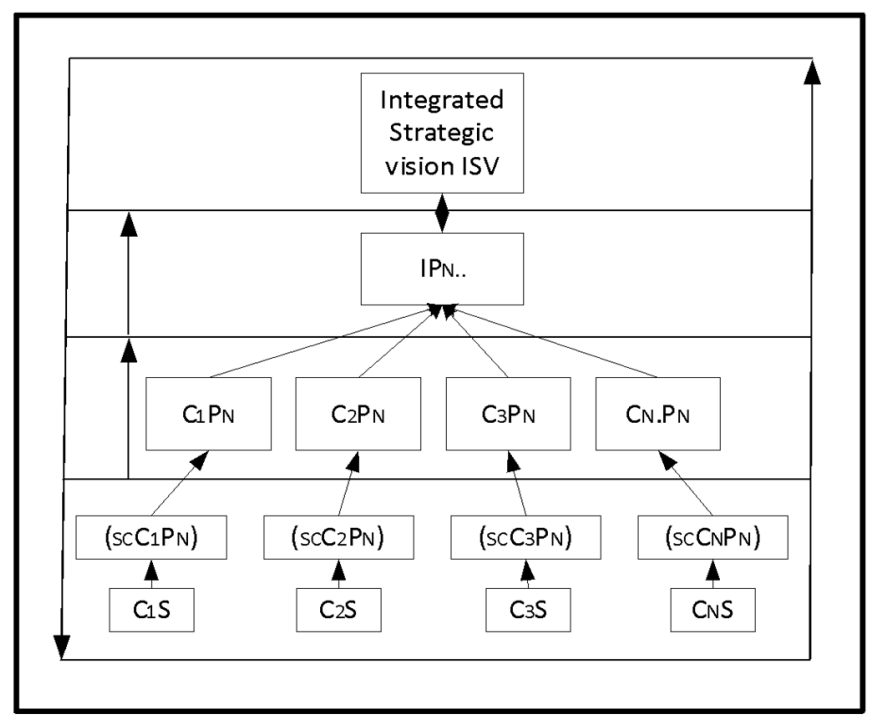

Source: Prepared by the author

\section{FORMULATE THE INTEGRATION PRINCIPLES}

The aggregate sample principles collected $\left(\mathrm{CN}_{\mathrm{N}} \mathrm{P}_{\mathrm{N}}\right)$ resulted with many of the principles being similar in context. For example:

$\left(\mathrm{C}_{1} \mathrm{P}_{4}\right)$ Develop technology and infrastructure.

$\left(\mathrm{C}_{2} \mathrm{P}_{3}\right)$ Invest in technology and infrastructure.

$\left(\mathrm{C}_{3} \mathrm{P}_{2}\right)$ Invest in rail terminal technology.

$\left(\mathrm{C}_{4} \mathrm{P}_{1}\right)$ Invest in rail technology and infrastructure.

$\left(\mathrm{C}_{5} \mathrm{P}_{3}\right)$ Provide site for building.

The process of extracting individual principles resulted in more than a manageable number required to formulate the green-field strategy. Merging of superior principles enables eliminating and reducing duplicating ideas into a manageable number. The controlled convergence (Pugh, 1990) can be applied in reducing the number and to design a superior principles. However, the traditional controlled convergence method (Pugh, 1990) is slow and time demanding. An alternative faster approach based on recent literature recommendations (Perez-Franco et al., 2010) was developed for the formulation of a green-field strategy.
The process is illustrated in Figure 5 and can be summarised as:

- Characterise green-field integration through integration principles.

- Determine the fit and intensity to eliminate conflicting individual principles.

- Determine the impact integrating choices through merging principles.

- Determine validity of underlying factors as guiding force.

- Investigating the relationships in inter-organisational integration.

By applying the process through 3 rounds, the probability of specific groups establishing preferred principles according to their industry interests was eliminated. The changes in the approach are made to avoid the element of individual preference that could have created a conflict of interest in the segmentation process.

a) First segmentation: (1) individual validation of the green-field principles, (2) executives identify preferred principles, (3) validation of the relationship, (4) validating the integration elements.

b) Second segmentation: sub-groups identify the most relevant principles to attaining superior principles, and to detect duplicated concepts in the principles.

c) Third segmentation: group discussion with the supply chain participants on the superior principles.

Figure 5: Formulating integration principles from the individual principles

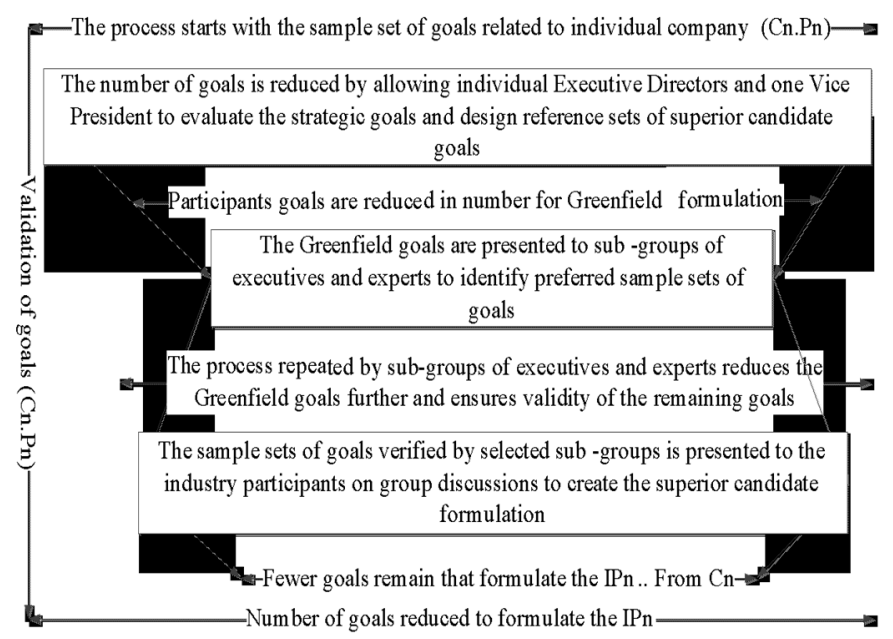

Source: Prepared by the author

The method in Figure 5 is designed and applied to: a) validate the individual principles, b) obtain additional principles, c) reduce the list and hierarchically classify the principles. In the process the following criteria is considered: 
- It was agreed with the participants that the superior sample set of principles (IPN) should preserve the relationship with integration of the principles from $\left(\mathrm{C}_{\mathrm{N}} \cdot \mathrm{P}_{\mathrm{N}}\right)$ to define integrated principles $\left(\mathrm{IPN}_{\mathrm{N}}\right)$ architecture (ISV) for the supply chain strategy.

- It was agreed with the group A and B participants that it was necessary for the (ISV) to representative of the interests of all companies expressed in the ( $\mathrm{sCCN} . \mathrm{PN}_{\mathrm{N}}$ ) in the consortium and for the individual principles $\left(\mathrm{CN}_{\mathrm{N}} \mathrm{PN}\right)$ to be integrated in the context of the green-field formulation principles $\left(\mathrm{IPN}_{\mathrm{N}}\right)$.

- Through group discussions with individual companies, it was confirmed that the (ISV) should evolve to be representative of the individual and greenfield strategic principles (IPN).

- The process resulted with superior principles (IPN) through merging the existing principles $\left(\mathrm{C}_{\mathrm{N}} . \mathrm{PN}_{\mathrm{N}}\right)$ to update the list, in the process the pre-established reference principles served as sample guidance for investigating the relationship between the $\left(\mathrm{C}_{\mathrm{N}} \cdot \mathrm{P}_{\mathrm{N}}\right)$ and $(\mathrm{SD})$ resulting with the $\left(\mathrm{IPN}_{\mathrm{N}}\right)$.

- Several repetitions were performed, including one repetition with each participant $\left(\mathrm{CN}_{\mathrm{N}} \mathrm{PN}\right)$ to identify the best possible $(\mathrm{IPN})$ principles where integration is considered to identify alternatives to the references.

\subsection{Conversion of tacit into explicit green-field ar- chitecture}

The degree of complexity confirms that if strategy is left tacit, there is a possibility of conflicting interests to emerge. For example, while the executive director of $\left(\mathrm{C}_{1}\right)$ wanted the green-field strategy to cover 'world-wide markets', the executive director of $\left(\mathrm{C}_{3}\right)$ wanted the green-field strategy to cover only the surrounding areas where the company terminals were based. Such conflicting areas could lead the formulation away from integration. Also, in certain cases it was discovered that the companies were not aware themselves of the contribution of how useful their specific knowledge to the formulated strategy could be. This was caused mainly because their expertise is a tacit knowledge and as such is not easy to record and share.

\subsection{Relationship between green-field architecture and principles}

The method applied served as a narrowing enquiry to merge similar principles aimed at keeping the ideas not the wording. The method confirmed that the strategic architecture must represent the interests of all the participant industries and the principles must be focused on achieving the architecture. The process is aimed at visualising the problem, avoiding confusion and bringing the focus on the common principles.

The process of formulating the new set of principles included: 1. designing a sample set of individual principles $\left(\mathrm{C}_{\mathrm{N}} . \mathrm{PN}_{\mathrm{N}}\right), 2$. Creating a smaller sample set of green-field reference principles and relating them to the $(\mathrm{SD}), 3$. Validate the $\left(\mathrm{IPN}_{\mathrm{N}}\right)$ principles and ensure coverage through group discussion. This resulted in the strategic principles broadly defined by the group in a few sentences as:

1. 'Supply enough by-product to match the current demand and fulfil the demand of potential new markets for recycled secondary aggregate' (Market demand dimension).

2. 'Make the best use of engineering and technology for transporting slate aggregate to markets by rail and sea' (Technology dimension).

3. 'Achieve economic and environmental sustainability for the aggregate supply chain' (Environmental dimension).

4. 'Have a cost-effective transportation system to move the aggregate from the quarry to the point of sale' (Transportation dimension).

5. 'Maximise the volume of our sales of slate aggregate to the market' (Resource dimension).

Through group discussions among the executives and managers of the consortium companies participating in the formulation, the managers reached the conclusion that what unites their companies is their mutual desire for the 'increased sales of secondary aggregate'. The (IPN) sample set of principles is summarised into a new architecture (ISV): 'Commercialise the secondary aggregate...'. This sentence represented the strategy core in the form of a jointly defined strategic architecture. The validated architecture and pillars were built into a conceptual diagram (Figure 6) representing the green-field business strategy. 
Figure 6: Greenfield business architecture formulated in the case study

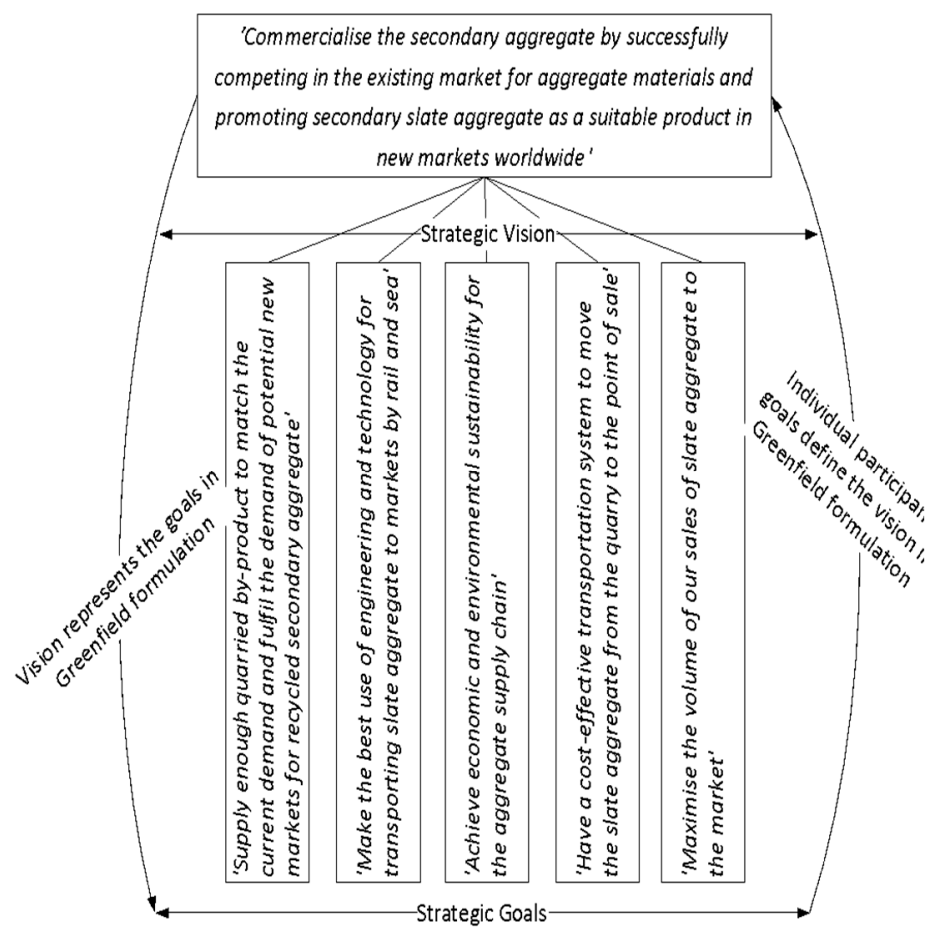

Source: Prepared by the author

\subsection{Critical Analysis of the conceptual system}

The pursuit for validity of the conceptual system applied the qualitative research techniques recommended in Perez-Franco et al., (2010) for open and categorical coding analysis of qualitative data. This resulted with a formulation of a green-field business strategy that ensured integration on two levels:

1. Integration and anticipation of complexities when multiple industries are involved.

2. Ensures that the green-field principles support, compliment and enable the integrated architecture.

These steps represent the starting point of the integration design, where the formulation criteria are determined by identifying areas of the business strategy that provide insights for the supply chain strategy formulation. The second step is hierarchically linking the formulation criteria by referring to the evaluation criteria to formulate the supply chain strategy. The following evaluation criteria emerged from the formulation:

1. Feasibility, the formulation must ensure that every concept is feasible (Andrews et al., 2009, Inkpen and Choudhury, 1995), and must be focused on 'accepting' and 'acting' upon reality (Pettigrew, 1977).

2. Sufficiency, the formulation needs to consider concepts as objectives to be satisfied by the support received. Without sufficient coverage the supply chain strategy cannot be executed effectively in sustaining the 'goals' of the integrated companies. The evaluation criterion is based on visibility (Inkpen and Choudhury, 1995, Fisher, 1997).

3. Support, individual formulation criteria must be targeted at providing support to at least one of the concepts with higher ranking in the conceptual framework. The evaluation criterion is based on participation (Menda and Dilts, 1997, Karl-Erik, 2001, Zhou and Chen, 2001, Qureshi et al., 2009), communication (Tracey et al., 1999), and formality (Andrews et al., 2009). This criterion is reinforced with the clarification criterion 'adapting and alignment' and is based on: acceptance (Saad et al., 2002), adaptability (Sakka et al., 2011, Saad et al., 2002).

4. Compatibility the formulation must harmoniously coexist with all other concepts. The criterion is focused on 'flexibility' (Narasimhan and Das, 1999, Beamon, 1999, Kim, 2006). Compatibility can be contextualised in the form of synergies in the context of integration (Bozarth et al., 2009).

The evaluation and clarification criteria are designed to address the main weaknesses identified in existing literature in the context of supply chain strategy formulation. The criteria also represent elements that are valuable in turning the focus towards operationalization. This process simplified the idea behind the architecture and the principles that formulated the integrated business strategy. Open coding provided a reliable representation of the data collected, while categorical coding subsequently recognised the insights from the data and the 'profounder concepts' (Goulding 2002). Considering that the strategic architecture is the fundamental aspect of the green-field formulation and the strategic principles assist and enable the strategic architecture in integrating the principles behind the architecture, the 'profounder concepts' of the conceptual system derived with a number of conclusions:

1. Validating the integration between architecture and principles in business strategy is instrumental for linking accurately the coverage with the supply chain activities.

2. Strategy validity and coverage of the green-field business strategy is crucial for accomplishing the strategic principles of individual participants.

3. The integration process requires focus on strategic principles that are linked to the main activities.

4. Therefore, the strategic architecture depends on the success of the strategic principles applied jointly and individually.

To visualise the effect of these findings a new conceptual diagram is presented (Figure 7). The system 
is redesigned accordingly to ensure validity and visibility. This enabled presenting interdisciplinary integration concepts in a diagram involving multiple principles and confirming that strategic principles influence the strategic architecture.

Figure 7: Conceptual system for Formulation of green-field integration business and supply chain strategy

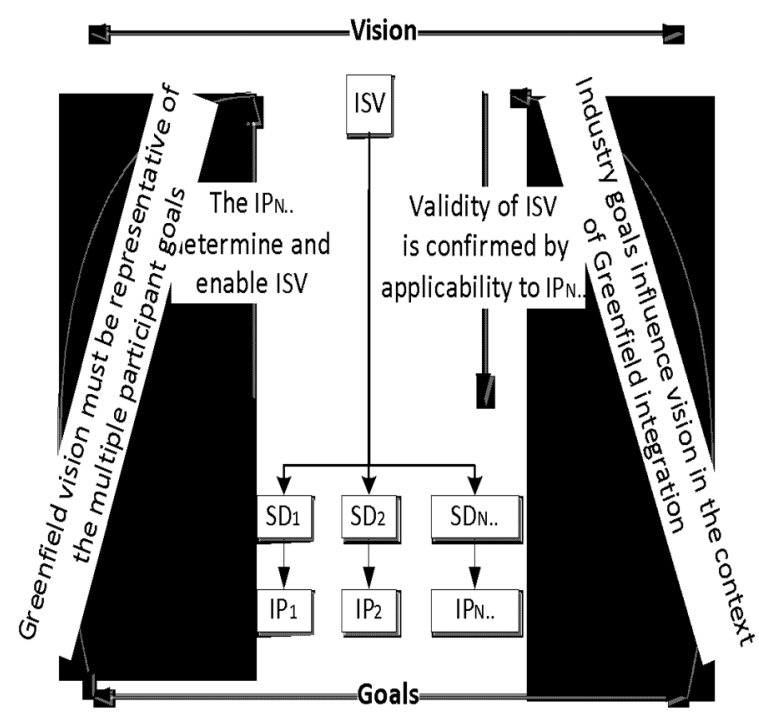

Source: Prepared by the author

The green-field business architecture as a formulation concept enabled the research to determine a method that links the interdisciplinary concept arising from involving multiple participants. Also this resulted in determining that the set of integrated strategic principles $(\mathrm{IPN})$ influence the integrated architecture (ISV). In other words, the multiple principles determine the architecture, while the architecture must represent the principles. In other words, the principles define the architecture and the architecture defines the principles and can be seen as a system of tasks.

\section{CONCLUSION}

This study builds upon existing literature on integrating business and supply chain strategy (Kaplan and Norton 1996, Frohlich and Westbrook 2001, Jayaram and Tan 2010, Bryceson and Slaughter 2010, Prajogo and Olhager 2012, Sukati et al. 2012), to derive with a new conceptual system architecture for green-field integration, based on earlier literature on supply chain reformulation (Perez-Franco et al., 2010, Qu et al.
2010, Sakka et al., 2011, Córdova et al., 2012, Leng and Chen, 2012).

The conceptual system for integrating individual principles into green-field business strategy formulation (Figure 6), derived with the conclusion that the business objectives represent an architecture that serves as a central idea that is best articulated through the integrated operational capabilities and the individual operational strategies (Figure 7).

The novelty of the conceptual system is in the engineering of integrated architecture and design. The conceptual system analyses and addresses the strategy abstention and absence of operational capabilities and evaluates the strategy engineering to determine the right level of integration design. The new process is based on extracting, evaluating and relating individual interests into integrated principles.

The study derived conclusions through the case study and concluded that making strategy explicit is essential in the strategy integration process. The evidence based case study confirmed that this approach is ac-

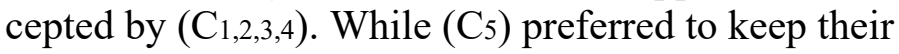
strategy implicit and not to be revealed, because it could leave them open to competitors. To address this obstacle, the articulation approach was restructured and documented, to serve as a tool for future research studies that are presented with this obstacle. The synthesis of the concepts and ideas, of the routine problems and issues related to architecting integrated green-field strategy, concluded that tacit strategic interests are required in an explicit form for the integration of the strategic principles to be considered representative of a supply chain consortium.

The new process can be applied to eliminate the complexities in a situation where absence of complete or consistent data or information is present when formulating a green-field supply chain. The conceptual system designed a green-field integration strategy. The process involved categorising individual supply chain strategic interests and defining the integration strategy as a system of concepts. This research contributed to knowledge with advancement of the design engineering method, which enables visualisation of the supply chain strategy process. The design is not personalised for individual company business strategy or supply chain strategy formulation. The method was 
personalised to evaluate the integration of individual goals, and concepts in a supply chain strategy formulation.

The novelty that emerged from this research was a conceptual system for green-field project architecture and integration design.

\subsection{Limitations of the study}

The conceptual design is aimed at generalising the idea behind the green-field project formulation for the mining supply chain strategy, to other sectors. However, this study involved a single case study and while it is anticipated that the proposed conceptual framework is suitable for other sectors, the findings would need to be delimited through further research.

The research methodology recognises that there is ambivalence in generalising the findings based on diversity as opposed to representativeness. The first challenge is represented in the relationship between the concepts, (ex. product family and the supply chain strategy) and is exposed to uncertainties when taken out of the context of the mining industry. A second challenge became clearer when attempting to compare the results between industries. If it is possible to synthesise data in one industry but not in another, the research will end up describing different industries, but would not be able to compare them by applying the same formulation parameters. The third challenge can be anticipated in using qualitative interviews for specific data collection in a small industry, such as the mining industry in North Wales. The size of the industry increases the possibility of bias and distortions in the conclusions, while the sensitive data would be difficult to collect. The fourth challenge future research studies will face in extracting tacit knowledge and converting it into explicit, is the preference towards desired over feasible principles. This issue becomes one of a degree in an integration scenario if a researcher is faced with the responders' avoidance of criticism, conflict, disagreement, and controversy. Future research studies should be aware that these challenges will occur, regardless of confidentiality agreements.

\subsection{Future research avenues}

The investigation into the strategic operational activities in this research is aimed at designing operational green-field formulation. The new design brings strategy dynamics through the feedback mechanisms, where strategy absence effectively disables the feedback mechanisms. Further research is required into the topic of addressing strategy absence, because in such scenarios, the formulation would be difficult to implement. A series of publications follows this research 1,2,11-20,3,21-30,4-1031,32

\section{REFERENCES}

Andrews, R. B., George A. Law, J. W., Richard, M., 2009. Strategy Formulation, Strategy Content and Performance: An Empirical Analysis. Public Management Review, 11, pp. 1-22.

Bartolomei, J. C., M. Dahlgren, J., De Neufville, R., Maldonado, D., Wilds, J., 2007. Analysis and Applications of Design Structure Matrix, Domain Mapping Matrix, and Engineering System Matrix Framework. Citeseer, Thesis, MIT Press.

Beamon, B.M., 1998. Supply Chain Design and Analysis: Models and Methods. International Journal of Production Economics, 55(3), pp. 281-294

Bozarth, C.C., Warsinga, D.P., Flynnb, B.B., Flynn, E.J., 2009. The impact of supply chain complexity on manufacturing plant performance. Journal of Operations Management, 27(1), pp.78-93.

Bryceson, K.P. \& Slaughter, G., 2010. Alignment of performance metrics in a multi-enterprise agribusiness. International Journal of Productivity and Performance Management, 59(4), pp.325-350.

Charmaz, K. 2006. Constructing Grounded Theory: A Practical Guide Through Qualitative Analysis, Sage Publications Ltd.

Cigolini, R., Cozzi, M. \& Perona, M., 2004. A new framework for supply chain management. International Journal of Operations \& Production Management, 24(1), pp.7-41.

Clausing, D. P. 1992. Enhanced Quality Function Deployment (EQFD), Massachusetts Institute of Technology, MIT Center For Advanced Engineering Study. MIT Press.

Córdova, F. Durán, C., Sepúlveda, J., Fernández, A., Rojas, M., 2012. A Proposal of Logistic Services Innovation Strategy for a Mining Company. Journal of technology management \& innovation, 7(1), pp.175-185.

Dotoli, M. Fanti, M. P., Melonia., \& Zhoub, M.C., 2007. A multi-level approach for network design of integrated supply chains. International Journal of Production Research. 43 (20), pp 4267-4287

Dubois, A., Hulthén, K. \& Pedersen, A.-C., 2004. Supply chains and interdependence: a theoretical analysis. Journal of Purchasing and Supply Management, 10(1), pp.3-9.

Easterby-Smith, M. T., R. Lowe, A. 2002. Management Research: An Introduction, Sage Publications Ltd.

Eisenhardt, K. M. 1989. Building Theories From Case Study Re-search. Academy Of Management Review, 14(4), pp. 532-550.

Eppinger, S. D. W., Smith, R.P. Gebala, D.A. 1994. A Model-Based Method for Organizing Tasks in Product Development. Research in Engineering Design, 6 (1), pp.1-13.

Eriksson, P. K. K., A 2008. Qualitative Methods in Business Research. Sage Publications, London.

Fisher, M. L. 1997. What Is the Right Supply Chain for Your Product? Harvard Business Review, 75 (2), pp. 105-117.

Frohlich, M. \& Westbrook, R., 2001. Arcs of Integration: An International Study of Supply Chain Strategies. Journal of Operations Management. 19 (2001), pp. 185-200.

Goulding, C. 2002. Grounded Theory: A Practical Guide for Management, Business and Market Researchers, Sage Publications Ltd.

Gummesson, E. 2000. Qualitative Methods in Management Re-search, Sage Publications, Inc.

Hafeez, K., Griffiths, K.M., Griffiths, J., \& Naim, M.M., 1996. Systems design of a two-echelon steel industry supply chain. International Journal of Production Economics, 45(1-3), pp.121-130.

Hines, T. 2004. Supply Chain Strategies: Customer-Driven and Customer-Focused, Oxford, Butterworth-Heinemann.

Inkpen, A. \& Choudhury, N., 1995. The seeking of strategy where it is not: Towards a theory of strategy absence. Strategic Management Journal, 16(4), pp.313-323.

Ivanov, D., 2010. An adaptive framework for aligning (re)planning decisions on supply chain strategy, design, tactics, and operations. 
International Journal of Production Research, 48(13), pp.39994017.

Jayaram, J. \& Tan, K.-C., 2010. Supply Chain Integration with ThirdParty Logistics Providers. International Journal of Production Economics, 125 (2), pp. 262-271

Kaplan, R. \& Norton, D., 1996. Using the balanced scorecard as a strategic management system. Harvard Business Review (January/February): 74 (1), pp. 75-85

Karl-Erik, S. 2001. A Knowledge-Based Theory of the Firm to Guide in Strategy Formulation. Journal of Intellectual Capital, 2 (4), pp. 344-358.

Kim, D., 2006. Process chain: A new paradigm of collaborative commerce and synchronized supply chain. Business Horizons, 49(5), pp.359-367.

Leng, K. \& Chen, X., 2012. A genetic algorithm approach for TOCbased supply chain coordination. Applied Mathematics \& Information Sciences, 6 (3), pp. 767-774

Love, L., Priem, R. \& Lumpkin, G., 2002. Explicitly articulated strategy and firm performance under alternative levels of centralization. Journal of Management. 28 (5), pp. 611-627

Martínez-Olvera, C. \& Shunk, D., 2006. Comprehensive framework for the development of a supply chain strategy. International Journal of Production Research, 44(21), pp.4511-4528.

Melnyk, S.A., Narasimhan, R. \& DeCampos, H.A., 2013. Supply chain design: issues, challenges, frameworks and solutions. International Journal of Production Research, 52(7), pp.1887-1896.

Menda, R. \& Dilts, D., 1997. The manufacturing strategy formulation process: linking multifunctional viewpoints. Journal of Operations Management. 15 (4), pp. 223-241

Mentzer, J.T., DeWitt, W., Keebler, J.S., Min. S., Nix, N.W., Smith, C.D., Zacharia, Z.G., 2001. Defining Supply Chain Management. Journal of Business Logistics, 22(2), pp.1-25.

Miles, M. H., 1984. Qualitative Data Analysis: A Sourcebook of New Methods, Beverly Hills, Ca, Sage Publications.

Mintzberg, H., 1990. The design school: reconsidering the basic premises of strategic management. Strategic management journal. 11 (3), pp. 171-195,

Narasimhan, R. \& Das, A., 1999. Manufacturing agility and supply chain management practices. Production and Inventory Management Journal, 40(1), pp. 4-10.

Narasimhan, R., Kim, S.-W. \& Tan, K.-C., 2008. An Empirical Investigation of Supply Chain Strategy Typologies and Relationships to Performance. International Journal of Production Research, 46(18), pp.5231 - 5259.

Perez - Franco, R. J, Sheffi, Y. Silbey, S., Frey, D., Singh, M., Leveson, N. 2010. A Methodology to Capture, Evaluate and Reformulate a Firm's Supply Chain Strategy as a Conceptual System. PhD Thesis, MIT Press

Pettigrew, A. M. 1977. Strategy Formulation as a Political Process. International Studies of Management \& Organization, 7 (2), pp.7887.

Prajogo, D., \& Olhager, J., 2012. Supply chain integration and performance: The effects of long-term relationships, information technology and sharing, and logistics integration. International Journal of Production Economics, 135(1), pp.514-522.

Pugh, S., 1990. Total Design: Integrated Methods for Successful Product Engineering, Addison-Wesley Wokingham, UK.
Qu, T. Huanga, G. Q., Cungb, V., \& Mangioneb, F., 2010. Optimal configuration of assembly supply chains using analytical target cascading. International Journal of Production Research, 48(23), pp.6883-6907.

Quinn, J. B., 1977. Strategic Principles: Process and Politics. Sloan Management Review, 21(4), pp.21-37.

Qureshi, M. N., Kumar, P., \& Kumar, D., 2009. Selection of Transportation Company: An Analytic Network Process Approach. Icfai Journal of Supply Chain Management, 6(2), pp.26-38.

Saad, M., Jones, M. \& James, P., 2002. A review of the progress towards the adoption of supply chain management (SCM) relationships in construction. European Journal of Purchasing \& Supply Management, 8(3), pp.173-183.

Sakka, O., Millet, P.A. \& Botta-Genoulaz, V., 2011. An ontological approach for strategic alignment: a supply chain operations reference case study. International Journal of Computer Integrated Manufacturing, 24(11), pp.1022-1037.

Schnetzler, M.J., Sennheiser, A. \& Schönsleben, P., 2007. A decomposition-based approach for the development of a supply chain strategy. International Journal of Production Economics, 105(1), pp.21-42.

Sukati, I., Hamid, A.B., Baharun, B., Yusoff. R.M.,, 2012. The Study of Supply Chain Management Strategy and Practices on Supply Chain Performance. Procedia - Social and Behavioral Sciences, 40, pp.225-233.

Tracey, M., Vonderembse, M.A. \& Lim, J.-S., 1999. Manufacturing technology and strategy formulation: keys to enhancing competitiveness and improving performance. Journal of Operations Management, 17(4), pp.411-428.

Zhou, S. \& Chen, R., 2001. A decision model for selecting participants in supply chain. Journal of Shanghai University (English Edition), 5(4), pp.341-344.

1. Nicolescu, R., Huth, M., Radanliev, P. \& De Roure, D. Mapping the values of IoT. J. Inf. Technol. 1-16 (2018). doi:10.1057/s41265-018-0054-1

2

Taylor, P., Allpress, S., Carr, M., Lupu, E., Norton, J., Smith, L., Blackstock, J., Boyes, H., Hudson-Smith, A., Brass, I., Chizari, H., Cooper, R., Coulton, P., Craggs, B., Davies, N., De Roure, D., Elsden, M., Huth, M., Lindley, J., Maple, C., Mittelstadt, B., Nicolescu, R., Nurse, J., Procter, R., Radanliev, P., Rashid, A., Sgandurra, D., Skatova, A., Taddeo, M., Tanczer, L., Vieira-Steiner, R., ... R.J., Westbury, P. S. Internet of Things realising the potential of a trusted smart world. (2018).

3. Radanliev, P., De Roure, D., Nurse, J. R., Burnap, P., Anthi, E., Ani, U., ... Mantilla Montalvo, R. Cyber risk from IoT technologies in the supply chain-discussion on supply chains decision support system for the digital economy. Univ. Oxford (2019). doi:10.13140/RG.2.2.17286.22080

4.

Radanliev, P., Charles De Roure, D., Nurse, J. R. C., Burnap, P. \& Montalvo, R. M. Methodology for designing decision support supply chain systems for visualising and mitigating cyber risk from IoT technologies. Working paper. (2019). doi:10.13140/RG.2.2.32975.53921

5. Radanliev, P., De Roure, D. C., Nurse, J. R. C., Montalvo, R. M. \& Burnap, P. The Industrial Internet-of-Things in the Industry 4.0 supply chains of small and medium sized enterprises. Working paper. (2019). doi:10.13140/RG.2.2.14140.49283 
6. Radanliev, P., Roure, D. C. De, Nurse, J. R. C., Burnap, P., Eirini Anthi, Ani, U., ... Montalvo, R. M. Design principles for cyber risk impact assessment from Internet of Things (IoT). Wokring paper. (2019). doi:10.13140/RG.2.2.33014.86083

7. Radanliev, P., De Roure, D. C., Nurse, J. R. C., Rafael, M. M. \& Burnap, P. Supply Chain Design for the Industrial Internet of Things and the Industry 4.0. (2019). doi:10.13140/RG.2.2.36311.32160

8. Radanliev, P., De Roure, D. C., Nurse, J. R. C. C., Nicolescu, R., Huth, M., Cannady, S. \& Montalvo, R. M. New developments in Cyber Physical Systems, the Internet of Things and the Digital Economy - future developments in the Industrial Internet of Things and Industry 4.0. (2019). doi:10.13140/RG.2.2.14133.93921

9. Radanliev, P. Supply Chain Systems Architecture and Engineering Design: Green-field Supply Chain Integration. Oper. Supply Chain Manag. An Int. J. 9, (2016).

10. Radanliev, P., Charles De Roure, D., Maple, C., Nurse, J. R. C., Nicolescu, R. \& Ani, U. Cyber Risk in IoT Systems. Journal of Cyber Policy (2019). doi:10.13140/RG.2.2.29652.86404

11. Radanliev, P., De Roure, D., Nicolescu, R., Huth, M., Montalvo, R. M., Cannady, S. \& Burnap, P. Future developments in cyber risk assessment for the internet of things. Comput. Ind. 102, 14-22 (2018).

12. Radanliev, P., De Roure, D., Nurse, J. R. C., Nicolescu, R., Huth, M., Cannady, S. \& Montalvo, R. M. Cyber Security Framework for the Internet-of-Things in Industry 4.0. (2019). doi:10.13140/RG.2.2.32955.87845

13. Radanliev, P., Rowlands, H. \& Thomas, A. Supply Chain Paradox: Green-field Architecture for Sustainable Strategy Formulation. in Cardiff: Sustainable Design and Manufacturing 2014, Part 2, International Conference (eds. Setchi, R., Howlett, R. J., Naim, M. \& Seinz, H.) 839-850 (Future Technology Press, 2014).

14. Radanliev, P. A conceptual framework for supply chain systems architecture and integration design based on practice and theory in the North Wales slate mining industry. (British Library, 2014). doi:ISNI: 0000000453526866

15. Radanliev, P. Architectures for Green-Field Supply Chain Integration. J. Supply Chain Oper. Manag. 13, (2015).

16. Radanliev, P., Roure, D. C. De, Nurse, J. R. C., Burnap, P., Anthi, E., Ani, U., ... Montalvo, R. M. Definition of Internet of Things (IoT) Cyber Risk - Discussion on a Transformation Roadmap for Standardisation of Regulations, Risk Maturity, Strategy Design and Impact Assessment. (Preprints, 2019). doi:10.13140/RG.2.2.17305.88167

17. Radanliev, P., De Roure, D., Cannady, S., Montalvo, R. ., Nicolescu, R. \& Huth, M. Economic impact of IoT cyber risk - analysing past and present to predict the future developments in IoT risk analysis and IoT cyber insurance. in Living in the Internet of Things: Cybersecurity of the IoT - 20183 (9 pp.) (Institution of Engineering and Technology, 2018). doi: $10.1049 / \mathrm{cp} .2018 .0003$

18. Radanliev, P. Green-field Architecture for Sustainable Supply Chain Strategy Formulation. Int. J. Supply Chain Manag. 4, 62-67 (2015).

19. Nicolescu, R., Huth, M., Radanliev, P. \& De Roure, D. State of The Art in IoT - Beyond Economic Value. (2018).
20. Radanliev, P., De Roure, D., Nurse, J. R. C. C., Nicolescu, R., Huth, M., Cannady, S. \& Montalvo, R. M. Cyber risk impact assessment - assessing the risk from the IoT to the digital economy. (2019). doi:10.13140/RG.2.2.11145.49768

21. Nurse, J. R. C., Radanliev, P., Creese, S. \& De Roure, D. Realities of Risk: 'If you can't understand it, you can't properly assess it!': The reality of assessing security risks in Internet of Things systems. in Living in the Internet of Things: Cybersecurity of the IoT - 2018 1-9 (The Institution of Engineering and Technology, 2018). doi:10.1049/cp.2018.0001

22. Radanliev, P., De Roure, D., Nicolescu, R. \& Huth, M. A reference architecture for integrating the Industrial Internet of Things in the Industry 4.0. Working paper. (2019). doi:10.13140/RG.2.2.26854.47686

23. Radanliev, P., De Roure, C. D., Nurse, .R.C., Nicolescu, R., Huth, M., Cannady, C. \& Montalvo, R. M. Integration of Cyber Security Frameworks, Models and Approaches for Building Design Principles for the Internet-of-things in Industry 4.0. in Living in the Internet of Things: Cybersecurity of the IoT -

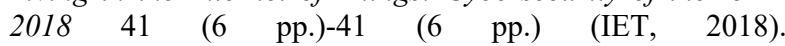
doi:10.1049/cp.2018.0041

24. Radanliev, P., Roure, D. De, Nurse, J. R. C., Nicolescu, R., Huth, M., Cannady, S. \& Montalvo, R. M. New Developments in Cyber Physical Systems, the Internet of Things and the Digital Economy - Discussion on Future Developments in the Industrial Internet of Things and Industry 4.0. (2019). doi:10.20944/PREPRINTS201903.0094.V1

25. Radanliev, P., De Roure, D., Cannady, S., Montalvo, R. M., Nicolescu, R. \& Huth, M. Analysing IoT cyber risk for estimating IoT cyber insurance. (2019). doi:10.13140/RG.2.2.25006.36167

26. Radanliev, P., De Roure, D. C., Nurse, J. R. C., Montalvo, R. M. \& Burnap, P. Standardisation of cyber risk impact assessment for the Internet of Things (IoT). (2019). doi:10.13140/RG.2.2.27903.05280

27. Radanliev, P. Engineering Design Methodology for GreenField Supply Chain Architectures Taxonomic Scheme. J. Oper. Supply Chain Manag. 8, 52-66 (2015).

28. Radanliev, P., DeRoure, D., Nurse, J. R. C., Burnap, P., Anthi, E., Ani, U., ... Montalvo, R. M. Definition of Cyber Strategy Transformation Roadmap for Standardisation of IoT Risk Impact Assessment with a Goal-Oriented Approach and the Internet of Things Micro Mart. Working paper. (2019). doi:10.13140/RG.2.2.12462.77124

29. Radanliev, P., Roure, D. C. De, Nurse, J. R. C., Burnap, P., Anthi, E., Ani, U., ... Montalvo, R. M. Cyber risk from IoT technologies in the supply chain-decision support system for the Industry 4.0. (2019). doi:10.13140/RG.2.2.17286.22080

30. Radanliev, P., Roure, D. De, Nurse, J. R. C., Nicolescu, R., Huth, M., Cannady, S. \& Montalvo, R. M. Cyber Risk impact Assessment - Assessing the Risk from the IoT to the Digital Economy. Univ. Oxford (2019). doi:10.20944/PREPRINTS201903.0109.V1

31. Radanliev, P. Cyber Risk Management for the Internet of Things. Univ. Oxford (2019).

32. Radanliev, P. CYBER RISK IMPACT ASSESSMENT. Univ. Oxford (2019).

Dr Petar Radanliev is a Postdoctoral Research Associate at the University of Oxford. Dr Radanliev holds a Ph.D. in Technology from the University of South Wales, MSc (Econ) and BA (Hons) from University of Wales, Aberystwyth. In 2010, Dr Petar Radanliev was awarded a Prince of Wales Innovation Scholarship and has been working on collaborative research with MIT-ILP on the 'Supply Chain 2020' project. His primary areas of research are: supply chain and smart city design, green-field architectures and environmental science and technologies. 